ORIGINAL ARTICLE

\title{
Functional state dynamics in cross-country skiers in the summer and autumn preparatory phase
}

\author{
Igor O. Garnov ${ }^{\mathrm{ABD}}$, Tatyna P. Loginova ${ }^{\mathrm{AB}}$, Nina G. Varlamova ${ }^{\mathrm{CB}}$, Natalya N. Potolitsyna ${ }^{\mathrm{DB}}$, Alexey A. Chernykh ${ }^{\mathrm{BCD}}$, \\ Evgeny R. Bojko ${ }^{\mathrm{ADE}}$ \\ Institute of Physiology of the Komi Science Centre of the Ural Branch of the Russian Academy of Sciences, Russian
Federation
}

Authors' Contribution: A - Study design; B - Data collection; C - Statistical analysis; D - Manuscript Preparation; E - Funds Collection

\begin{abstract}
Purpose:

To study changes in the functional state of professional Russian cross country skiers in the course of the preparatory phase and their effects on their competition ratings.

Material:

In this study we examined 10 cross-country skiers. The functional state was assessed through a maximal load bicycle ergometer test, coordination and special performance tests. Concentrations of lactate and cortisol were checked in the blood plasma of participants.

Results:

The training effects on general physical preparedness and special physical preparation in September in comparison with June were observed as an increased number of pull-ups on a pull-up bar (by 14\%) and decreased time of the roller ski test (by $4 \%$ ). In autumn higher systolic (by $11 \%$ ) and diastolic (by 10\%) arterial blood pressure levels, higher levels of plasma lactate and cortisol (by $48 \%$ and $64 \%$, respectively) were detected $(p<0.05)$. At anaerobic threshold the following increased: total performance capacity (by $13 \%)$, oxygen consumption (by $14 \%$ ), watt pulse (by $5 \%$ ), respiratory minute volume, oxygen utilization coefficient, and oxygen pulse (by 15\%) $(\mathrm{p}<0.05-0.01)$ at rest before the ergometer test. In September upon completion of the ergometer test we observed an increase of oxygen pulse (by $7 \%$ ), watt pulse (by $10 \%)$, and oxygen utilization coefficient (by $24 \%)(p<0.05)$. In autumn at the 5 th minute of recovery after the ergometer test the heart rate recovered $11 \%$ faster, blood lactate $-29 \%$ faster, and the oxygen utilization rate increased by $15 \%(p<0.05-0.01)$. In June no statistically significant correlations were found between the studied indicators. In autumn statistically significant correlations appeared between indicators of the cardiorespiratory system, physical performance, and coordination test time.

Conclusions: The package program for the summer-autumn training period contributes to the improvement of the functional status of the cross-country skiers and to the development of physical power, endurance, increased strength of the upper limbs, increased speed of movement on roller skis, faster and more complete recovery of physiological and biochemical parameters.

Keywords: $\quad$ physical performance, cross-country skiers, anaerobic threshold, preparatory phase, coordination movements.
\end{abstract}

\begin{abstract}
Introduction
Cross-country skiing requires an athlete to develop endurance, which depends on aerobic performance. Sprint races and mass starts in competitions determine the ability to generate high level of muscle effort [1]. Assessment of functional state of organs and systems, which can change as a result of training exercises (TE), can be used by both scientists and coaches to obtain objective information on effects of the training process (TP) [2, 3]. According to the literature [1, 4], combined TE aimed at developing endurance and strength in the preparatory period (PP) contribute to lowering the intensity of the cardiorespiratory system (CRS), reducing blood lactate during exercise, and increasing maximum oxygen consumption $\left(\mathrm{VO}_{2}\right)$, which is reflected in improving sports results in the competition period. These were accompanied by higher performance and better results during competition period. It is known [4] that these indicators are partially determined by the activity of the neuromuscular apparatus, the development of which is facilitated by (c) Igor O. Garnov, Tatyna P. Loginova, Nina G. Varlamova,

Natalya N. Potolitsyna, Alexey A. Chernykh, Evgeny R. Bojko, 2021 doi:10.15561/26649837.2021.0302
\end{abstract}

strength training. However, combined TE are still being discussed among researchers, trainers and athletes [5]. Specialized literature does not give a decisive answer about the effects of combined TE during 16 microcycles of PP on the endurance development in cross-country skiers. Older studies [6-8] insist on the lack of positive effects on endurance, and more current ones [9] contradict those results. This might have been caused by different strategies in strength training of athletes in cyclic sports.

Significance. Modern studies [1, 4] are focused on describing of various training programs used in the preparatory phase (PP). Current studies $[1,4]$ are focused on describing of various training programs used in the preparatory phase (PP). However the available literature lacks reports on changes in general physical performance, special physical preparedness, physiological parameters in elite ski runners during 16 micro-cycles of TP in summer and autumn, when using combined TE.

The aim of the study was to assess the functional state of elite cross-country skiers during the TP in the summer and autumn PP and to draw connections with their competition ratings. 


\section{Materials and Methods}

Participants. This study was conducted in the Department of Ecological and Medical Physiology of the Institute of Physiology of the Komi Science Centre of the Ural Branch of the Russian Academy of Sciences (IPhys FCR Komi SC UB RAS) (Syktyvkar, Russian Federation) at the beginning (June) and the end (September) of the $\mathrm{PP}$ in 2018 in the morning and afternoon. Ten male professional ski runners, all masters of sports according to the Russian classification, participated in the study, two of them were in the Russian Federation ski team, and eight - in the Komi Republic team, age 22.5 $\pm 3.3 \mathrm{yr}$, height $178.5 \pm 5.6 \mathrm{~cm}$, RUS point - (RUS Race score is a universal assessment of the result shown by an athlete in a race of the CCSFR (Cross-country skiing Federation of Russia) calendar, compared to the race winner result) $149.0 \pm 70.0 \mathrm{pp}$. The athlete track record of all participants was 12-14 years. All participants signed informed consent for participating in the study. The protocol of the study was approved by the Committee on Bioethics of the Institute of Physiology of Komi SC UB RAS, and conformed to the Declaration of Helsinki.

Research design. Examination procedure. The height and body mass of participants were registered using height meter combined with medical scales (Russia), percentage of fat in body mass was measured with bioelectrical impedance meter Omron BF 302 (Omron, Japan). Vital capacity was determined using computerized spirograph SPM-01 R-D (Russia), systolic (SAP) and diastolic (DAP) arterial pressure was assessed by auscultating for Korotkoff sounds with the Microlife Model BP AG130 tonometer (Switzerland). The functional state of our participants was assessed by conducting a maximal bicycle ergometer test for determination of $\mathrm{VO}_{2} \max$; the test was performed with ergospirometric system Oxycon Pro (Erich Jaeger, Germany). The protocol of the ergometer test $[10,11]$, is presented in fig. 1 .

During the test several parameters - respiratory minute volume, breath rate, oxygen consumption, maximal oxygen consumption, heart rate - were registered in the "breath-by-breath" mode with averaging at 15-second intervals. At each stage of the test SBP and DBP were measured. The data were used for computation of respiratory volume, oxygen pulse, oxygen consumption percentage of maximal oxygen consumption at anaerobic threshold (AT), watt pulse, oxygen utilization coefficient. The performance capacity was registered at anaerobic threshold (AT). Capillary blood samples were obtained from each participant at rest, immediately after cessation of pedaling, and at the 5th minute of recovery. Levels of lactate (commercial kit, Sentinel, Italy) and cortisol (commercial kit, Alcor Bio, Russia) were assayed by enzyme-linked immunoassay with ChemWell 2900 analyzer (USA). The effects of PP and bicycle ergometer testing on motor coordination were evaluated by a test on a coordinimeter. Coordinimeter tests were conducted in the sitting position before and after bicycle ergometer testing lasting to muscular failure. Coordinimeter is a device with mobile upper and lower platforms joined by adjustable shaft for changing the height of the device. It is controlled by both arms and legs of a person under test. This allows measuring the time required for completion of the test for arms-and-legs coordination when they work as a single kinematic chain of movement [12].

Characteristics of TP. The main purpose of the 16 microcycles of PP was to develop both functional capabilities of the cardiorespiratory system and physical performance - endurance and strength. This aim was achieved by means of scheduled physical exercises. All participants followed the same training plan and had the same standardized diet that provided $6000 \mathrm{kkal} / \mathrm{day}$. The data on TE (in $\mathrm{km}$ and hours) and exercise intensity was obtained from personal heart rate monitors (Polar, Kempele, Finland).

The HR zones were computed from maximal HR data [10]. Recommendations for developing general physical preparedness and special performance were based on the five HR zone model, although it was suggested that during TE planning and implementation the participants didn't push themselves than the fourth zone. During PP a gradual increase of aerobic performance was achieved by stepwise building-up of the cyclic load in each HR zone (Fig. 1) while training general and specialized capacities.

In addition to increasing physical and special performance for the development of strength endurance in the summer stage (June - August), TE were used (Table 1), including $44.4 \%$ of strength exercises (circular method), in the fall (September) - 58.3\% (repeated method). Throughout the whole PP these TE were performed on the first and fourth days of the microcycle in the afternoon

\begin{tabular}{|c|c|c|c|c|c|c|c|c|c|c|c|}
\hline & & & & & & \multicolumn{3}{|c|}{...AT... } & & & \\
\hline \multicolumn{3}{|c|}{$\mathrm{W}, \mathrm{Wt}$} & 0 & 120 & 160 & 200 & $\ldots$ & 400 & & & \\
\hline \multicolumn{3}{|c|}{$\vec{\vartheta} \mathrm{rpm}$} & \multicolumn{6}{|c|}{60} & & & \\
\hline Time, min & 2 & 3 & 1 & 3 & 5 & 7 & $\ldots$ & 17 & 1 & 3 & 5 \\
\hline $\begin{array}{c}\text { Step } \\
\text { examination } \\
\text { procedure }\end{array}$ & \multicolumn{2}{|c|}{$\begin{array}{l}\text { position prone } \\
\text { siting }\end{array}$} & \multicolumn{6}{|c|}{ load } & \multicolumn{3}{|c|}{ recovery } \\
\hline $\begin{array}{c}\boldsymbol{V} \text { - assessed } \\
\text { SAD/DAD }\end{array}$ & & & $\boldsymbol{V}$ & $\boldsymbol{V}$ & $\boldsymbol{\varphi}$ & 0 & C & $\boldsymbol{\varphi}$ & $\mathbf{V}$ & 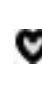 & $\boldsymbol{V}$ \\
\hline
\end{tabular}

Figure 1. The protocol of the ergometer test 
Table 1. Additional training protocol for cross-country skiing training

\begin{tabular}{|c|c|c|c|}
\hline June - August & & September & \\
\hline Exercises & Volume & Exercises & Volume \\
\hline 1. Wide grip pull-up & \multirow{14}{*}{$\begin{array}{l}\text { Two } \\
\text { rounds, ten } \\
\text { repetitions } \\
\text { each. }\end{array}$} & 1. Wide grip pull-up & \multirow{6}{*}{$\begin{array}{l}4 \times 12-16 \\
\text { repetition; } \\
2,5 \text { min recovery; } \\
4 \text { rounds, } 12-16 \\
\text { repetitions; }\end{array}$} \\
\hline 2. Bench dips on a $30 \mathrm{~cm}$ bench & & 2. Chest-focused dip & \\
\hline 3. Incline sit ups & & 3. Bench press & \\
\hline 4. Step ups on $50 \mathrm{~cm}$ platform & & 4. Smith machine barbell squat & \\
\hline 5. Squat jumps. & & 5. Barbell seal row & \\
\hline 4. Step ups on $50 \mathrm{~cm}$ platform & & 6. Walking lunges with dumbbells & \\
\hline 6. Back extensions (hyperextensions) & & 7. Seated cable row & \multirow{2}{*}{$\begin{array}{l}2,5 \text { minutes of } \\
\text { recovery; }\end{array}$} \\
\hline 4. Step ups on $50 \mathrm{~cm}$ platform & & & \\
\hline 5. Squat jumps & & & \multirow{6}{*}{$\begin{array}{l}40 \%-50 \% \text { of } \\
\text { maximal weight }\end{array}$} \\
\hline 6. Back extensions (hyperextensions) & & & \\
\hline 7. Parallel bar dips & & & \\
\hline 8. Box jumps $(50 \mathrm{~cm})$ & & & \\
\hline 9. Hanging leg raise & & & \\
\hline 10. Narrow push-up & & & \\
\hline
\end{tabular}

and preceded the high-intensity exercise on the following day.

Physical performance tests. At the beginning and at the end of PP benchmark TE were performed. Their purpose was to assess the levels of general physical preparedness (GPP) and special physical preparation (SPP). For specialized performance testing our participants did a roller ski free skating test according to the following protocol: first lap $(4 \mathrm{~km})$ - without poling, second lap $(4 \mathrm{~km})$ - with poling and increased arm work, third lap (4 km) - free skating. On the following day a physical performance test (maximum repetitions in one attempt) was performed: 1. Wide grip pull-up; 2. Chest-focused dip (maximum arm bending); 3. Hanging leg raise to touch the bar with feet.

Data on competition results in the NovemberDecember 2018 competition period (RUS points, rating positions obtained in the website of the Cross Country Ski Federation of Russia) [13] were used to assess and effectiveness on competition performance.

Statistical analysis. The data obtained were analyzed with Statistica software (v.6.0, StatSoft, USA). Normal distribution check was performed with Shapiro-Wilks test. The data reliability was assessed by Wilcoxon's W-test. Interrelationships between physiological parameters during the ergometer test, control physical performance tests, motor coordination and competition performance were assessed by Spearman's correlation coefficient. The data are presented as median and interquartile range $\left(25^{\text {th }}\right.$ and $75^{\text {th }}$ percentiles), (Me) $(25 \% ; 75 \%)$. Test results were considered significant at $\mathrm{p}<0,01-0,05$.

\section{Results}

The correlation between exercises at different heart rate zones and the total volume of cyclic load is presented in Fig. 2.

The results of our study are presented in table 2 and 3.

Tests of GPP и SPP showed statistically significant increase of strength endurance in wide grip pull-up (by $14 \%, p<0.05)$ from $24.0(21.0 ; 24.0)$ to $28.0(22.0 ; 29.5)$ rep and decreased time of the roller ski test (by $4 \%, \mathrm{p}<0.05$ ) from $1980.0(1914.0 ; 2017.0)$ to $1897(1897.0 ; 1978.0)$ sec. Remarkably, the lap time in roller ski test was significantly shorter (by $39 \mathrm{sec}$ ) in the first lap (without poling), other parameters tended to increase.

The results of testing coordination abilities in June and September did not differ statistically significantly. We marked falling trends in time: before the test on a bicycle ergometer in September compared to June, it decreased by $27.0 \mathrm{sec}$, from $85.0(71.5 ; 98.3)$ to 58.0 $(53.5 ; 93,7) \mathrm{sec}$, and after the test - by $13.0 \mathrm{sec}$, from $73.0(56.7 ; 92.5)$ to $60.0(51.2 ; 79.0) \mathrm{sec}$. To clarify the formation of a motor skill in the repeated testing on the coordinateometer, athletes were divided into two groups: those who performed the second test with shorter time and those who showed longer time. Thus, it was noted that $60 \%$ of the subjects improved the time of the second coordination test at the beginning of the PC, and $40 \%$ - at the end of the PC.

Dynamic of changes in physiological and biochemical parameters, body mass, percentage of fat in body mass, before and after the TP is shown in Table 2.

The analysis of biochemical parameters registered at rest before the test (Tab. 2) showed higher cortisol $(p<0.01)$ and lactate levels in blood $(p<0.05)$ in September in comparison with June. Also, SBP and DBP levels were significantly higher in September $(p<0.05)$. Other physiological parameters showed differing trends and remained within corresponding reference ranges.

In September compared with June on AT we observed significantly higher oxygen consumption $(p<0.01)$, respiratory minute volume $(\mathrm{p}<0.05)$, and power $(\mathrm{p}<0.05)$. Values of several calculated parameters - oxygen pulse, watt pulse, oxygen utilization coefficient on AT and upon completion of the bicycle ergometer test were also significantly increased in September $(p<0.01-0.05)$. 


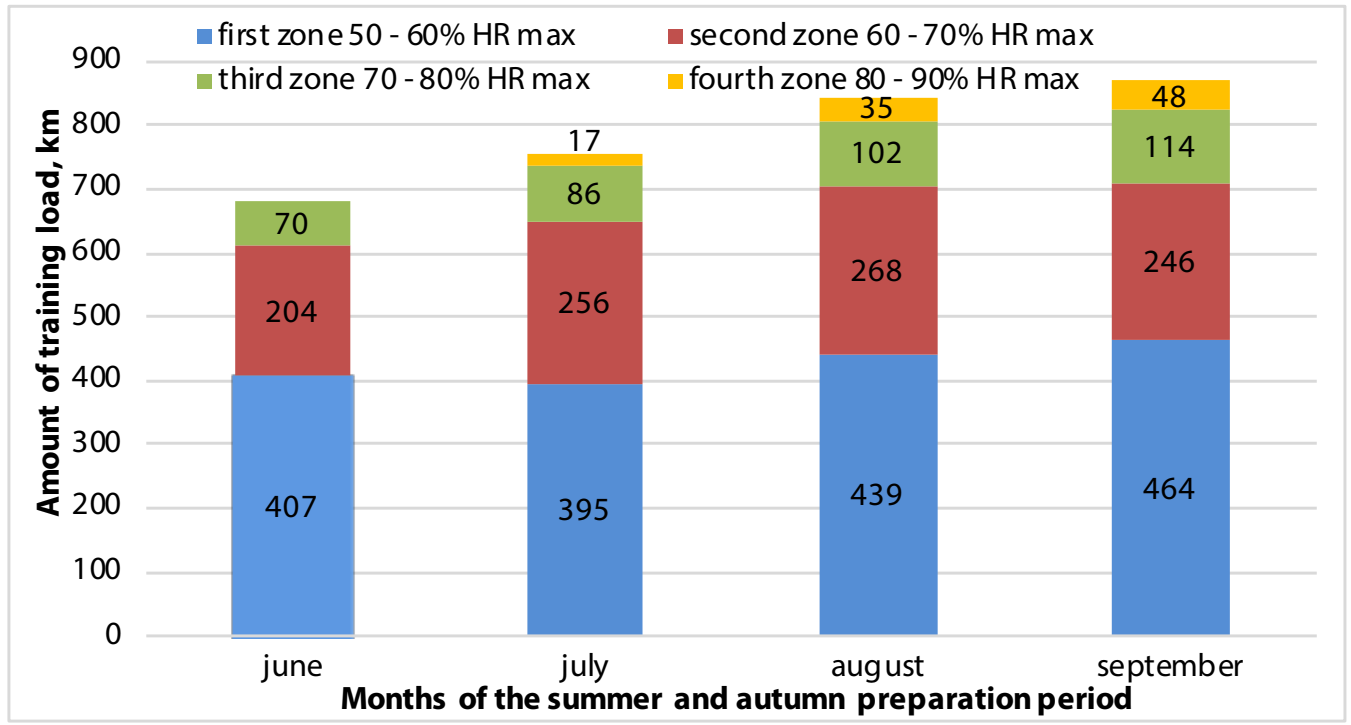

Figure 2. Relative amount of cyclic exercise in different HR zones in the total amount of cyclic exercises.

Also, in September at the $5^{\text {th }}$ minute of recovery after the ergometer test we observed a significant increase of oxygen utilization coefficient $(\mathrm{p}<0.05)$, and a decrease of heart rate and blood lactate level $(\mathrm{p}<0.05)$. Other parameters displayed diverse trends and also remained in their respective reference ranges.

In autumn we observed significant negative correlations between physiological parameters during the bicycle ergometer test and control TE, coordinimeter test times, and competition performance of ski runners (Tab. 3).

The correlation analysis showed a significant strong negative correlation between oxygen consumption at AT and time of the roller ski test (Tab. 4) and also between watt-pulse and coordination test time after the bicycle ergometer test to muscle failure, a mean negative correlation between $\mathrm{VO}_{2} / \mathrm{kg}$ in AT and RUS scores in sprint, AT load power and time of the special roller ski test, as well as between $\mathrm{VO}_{2}$ at the end of the test "to failure", load power and time of the second coordination test.

\section{Discussion}

Our results suggest that additional strength and speed training program was beneficial and increased strength endurance in athletes who participated in our study. Higher number of pull-up repetitions reflected increased strength and endurance of latissimus dorsi muscles, arm and forearm flexors, that are involved in poling [14]. We estimated the observed decrease of $12 \mathrm{~km}$ roller ski test time as a marker of increased specialized endurance in our participants [15]. Similar changes were noted in Norwegian skiers on the roller ski test after the 12-week PP [4]. In our opinion significantly better performance parameters in September were, a result of a successful training program.

Increased blood pressure values (both SBP and DBP) at rest before ergometer test in September were caused by both intensive physical training in previous months and by seasonal dynamics of circulatory system in its year cycle [16]. Increase in training intensity affected balances in vegetative nervous system, and caused changes in neuroendocrine function of adrenal cortex. In September we observed statistically significant $(p<0.01)$ increased blood cortisol levels. Being glucocorticoid hormone and therefore involved in developing endurance, cortisol is capable of causing hypertension if it is overproduced [16]. Trends towards increased blood pressure at rest before the ergometer test were observed previously in soldiers in September (in comparison with June; on average 118.9 (8.4) $\mathrm{mmHg}$ by 74.3 (4.2) $\mathrm{mmHg}$ and 114.7 (7.9) $\mathrm{mmHg}$ by $69.2(6.1) \mathrm{mmHg}$, respectively) [15]. We assume that in our study in athletes seasonal increases of SBP and DBP contributed along with other factors affecting BP - decreased air temperature [17] and increased blood cortisol levels - to the observed blood pressure increase. It is important to stress that despite being increased in September in comparison with June SBP and DBP parameters in our participants remained in normotonic reference range in both months.

Increased lactate levels at rest before the bicycle ergometer test observed in our study were possibly caused by both training regimen and by seasonal variation of that metabolite [17]. Our earlier observations showed that in the year cycle cross country skiers at rest demonstrate increased lactate levels in September in comparison with June $[2.3(1.9 ; 2.3) \mathrm{mmol} / \mathrm{l}$ against $1.8(1.5 ; 2.2) \mathrm{mmol} / \mathrm{l}$, respectively; $\mathrm{p}<0.001$; unpublished data]. Those changes were probably caused by increased physical activity (the beginning of the active training period) and, by increased amino acid utilization [17]. Amino acids are metabolized into tricarboxylic acid cycle and further oxidized through their transformation into pyruvate with increased glycolysis contributors to increased lactate levels at that time of the year.

Power is one of the parameters reflecting optimal functioning of the key physiological systems in performing specific physical tasks [1]. It is known that in cross country 
Table 2. Physiological and biochemical parameters of ski runners at the beginning and at the end of the training period

\begin{tabular}{|c|c|c|}
\hline Indicators & June & September \\
\hline Body mass, kg & $73.4(72.1 ; 74.9)$ & $72.6(70.8 ; 75.9)$ \\
\hline Percentage of fat in body mass, $\%$ & $12.2(9.6 ; 12.6)$ & $10.2(9.0 ; 10.7)$ \\
\hline \multicolumn{3}{|l|}{ Maximal power, Wt } \\
\hline In anaerobic threshold & 280.0(280.0;280.0) & $320.0(280.0 ; 320.0) *$ \\
\hline Upon completion of the ergometer test & $360.0(330.0 ; 400.0)$ & $360.0(330.0 ; 400.0)$ \\
\hline \multicolumn{3}{|l|}{ Systolic blood pressure, $\mathrm{mmHg}$} \\
\hline At rest, in seating position & 110.0(103.0;113.0) & 123.0(112.0;131.0) * \\
\hline At anaerobic threshold & 198.0(177.5;199.0) & $195.0(186.5 ; 207.5)$ \\
\hline Upon completion of the ergometer test & $202.0(180.0 ; 209.0)$ & 205.0(193.0;218.0) \\
\hline Recovery, $5^{\text {th }}$ minute & $127.0(122.0 ; 131.5)$ & $122.0(113.5 ; 136.5)$ \\
\hline \multicolumn{3}{|l|}{ Diastolic blood pressure, $\mathrm{mmHg}$} \\
\hline At rest, in sitting position & $72.0(70.0 ; 78.5)$ & $80.0(78.0 ; 88.0)^{*}$ \\
\hline At anaerobic threshold & $70.0(55.0 ; 86.0)$ & $75.0(67.0 ; 87.0)$ \\
\hline Upon completion of the ergometer test & $70.0(60.0 ; 90.0)$ & $68.0(60.0 ; 79.5)$ \\
\hline Recovery, $5^{\text {th }}$ minute & $68.0(55.5 ; 71.5)$ & $70.0(70.0 ; 78.0)$ \\
\hline \multicolumn{3}{|l|}{ Heart rate, bpm } \\
\hline At rest, in sitting position position & $63.0(60.2 ; 71.5)$ & $61.5(55.0 ; 66.8)$ \\
\hline At anaerobic threshold & 158.0(151.5;162.3) & 150.0(148.0;167.0) \\
\hline Upon completion of the ergometer test & 184.0(175.0;186.0) & $172.0(156.3 ; 180.8)$ \\
\hline Recovery, $5^{\text {th }}$ minute & $101.5(97.3 ; 106.0)$ & $90.0(80.3104 .5) *$ \\
\hline \multicolumn{3}{|l|}{ Oxygen consumption, $1 / \min$} \\
\hline At rest, in sitting position position & $0.346(0.281 ; 0.392)$ & $0.300(0.280 ; 0.342)$ \\
\hline At anaerobic threshold & $3.381(3.214 ; 3.437)$ & $3.926(3.505 ; 4.259) * *$ \\
\hline $\mathrm{VO}_{2} \max$ & $4.539(4.086 ; 4.651)$ & $4.462(4.231 ; 4.790)$ \\
\hline Upon completion of the ergometer test & $4.347(4.046 ; 4.433)$ & $4.380(3.953 ; 4.670)$ \\
\hline Recovery, 5th minute & $0.762(0.689 ; 0.908)$ & $0.754(0.683 ; 0,820)$ \\
\hline \multicolumn{3}{|l|}{ Breath rate, $\min ^{-1}$} \\
\hline At rest, in seating position & $13.0(11.2 ; 14.8)$ & $13.5(11.5 ; 16.0)$ \\
\hline In anaerobic threshold & $33.0(29.5 ; 35.3)$ & $32.0(31.0 ; 38.0)$ \\
\hline Upon completion of the ergometer test & $47.5(43.0 ; 53.7)$ & $39.5(37.0 ; 52.7)$ \\
\hline Recovery, $5^{\text {th }}$ minute & $25.0(22.5 ; 26.7)$ & $24.0(23.5 ; 24.7)$ \\
\hline \multicolumn{3}{|l|}{ Respiratory minute volume, I/min } \\
\hline At rest, in seating position & $10.5(9.3 ; 11.8)$ & $10.2(8.5 ; 11.8)$ \\
\hline In anaerobic threshold & $90.0(86.3 ; 98.3)$ & $106.0(89.0 ; 108.0)^{*}$ \\
\hline Upon completion of the ergometer test & 148.5(141.7;165.5) & $127.0(98.5 ; 183.7)$ \\
\hline Recovery, $5^{\text {th }}$ minute & $33.5(32.3 ; 36.5)$ & $27.0(26.0 ; 33.4)$ \\
\hline \multicolumn{3}{|l|}{ Oxygen pulse, $\mathrm{ml} / \mathrm{hr}$} \\
\hline At rest, in seating position & $5.5(4.4 ; 6.0)$ & $5.3(4.8 ; 5.8)$ \\
\hline In anaerobic threshold & $21.6(21.2 ; 22.0)$ & $25.4(23.3 ; 26.3)^{* *}$ \\
\hline Upon completion of the ergometer test & $23.5(23.0 ; 24.2)$ & $25.4(24.9 ; 26.0)^{* *}$ \\
\hline Recovery, $5^{\text {th }}$ minute & $7.7(6.8 ; 8.6)$ & $9.0(8.7 ; 9.9)$ \\
\hline \multicolumn{3}{|l|}{ Watt/pulse, w/beats } \\
\hline In anaerobic threshold & $1.8(1.7 ; 1.8)$ & $1.9(1.8 ; 2.0)^{*}$ \\
\hline Upon completion of the ergometer test & $1.9(1.8 ; 2.1)$ & $2.1(2.0 ; 2.1)^{*}$ \\
\hline
\end{tabular}


Table 2 (Cont.)

\begin{tabular}{lll}
\hline Oxygen utilization coefficient, $\mathrm{ml} / \mathrm{min}$ & & \\
\hline At rest, in seating position & $32.7(30.0 ; 35.0)$ & $32.1(28.1 ; 34.6)$ \\
In anaerobic threshold & $21.6(21.2 ; 22.0)$ & $25.4(23.3 ; 26.3)^{*}$ \\
Upon completion of the ergometer test & $27.0(25.1 ; 30.0)$ & $35.4(25.0 ; 38.4)^{*}$ \\
Recovery, $5^{\text {th }}$ minute & $22.4(21.3 ; 24.8)$ & $26.2(23.0 ; 28.8)^{*}$ \\
\hline Cortisol, mmol/l & & \\
\hline At rest, in seating position & $517.5(476.3 ; 590.8)$ & $801.5(693.0 ; 964.3)^{* *}$ \\
\hline Lactate, mmol/l & & \\
\hline At rest, in seating position & $1.4(1.3 ; 1.5)$ & $2.7(1.9 ; 3.0)^{*}$ \\
In anaerobic threshold & $4.9(4.3 ; 5.7)$ & $4.8(4.6 ; 5.5)$ \\
Upon completion of the ergometer test & $9.0(8.3 ; 9.8)$ & $6.7(6.1 ; 8.0)$ \\
Recovery, $5^{\text {th }}$ minute & $9.0(8.2 ; 10.2)$ & $6.4(5.6 ; 8.6)^{*}$ \\
\hline
\end{tabular}

NB: data are presented as Me (25\%; $75 \%)$. Differences between June and September were considered statistically significant at: ${ }^{*}-p<0,05 ;{ }^{* *}-p<0,01$

Table 3. Correlations between physical performance with special physical training and the competition results and results of the second coordination test

\begin{tabular}{lll}
\hline Indicators & $r S$ & $p$ level \\
\hline $\mathrm{VO}_{2} / \mathrm{kg}$ AT and time of roller ski test, sec & -0.881 & 0.001 \\
Watt pulse upon completion of the ergometer test, $\mathrm{Wt} / \mathrm{hr}$ and second & -0.803 & 0.05 \\
coordinimeter test times, sec & -0.785 & 0.05 \\
$\mathrm{VO}_{2} \mathrm{AT} / \mathrm{kg}, \mathrm{ml} / \mathrm{min} / \mathrm{kg}$ and RUS points in sprint & -0.729 & 0.01 \\
Load in AT, Wt and time of roller ski test, sec & & 0.05 \\
$\begin{array}{l}\text { Oxygen pulse upon completion of the ergometer test, } \mathrm{ml} / \mathrm{hr} \text { and second } \\
\text { coordinimeter test times, sec }\end{array}$ & -0.693 & \\
$\begin{array}{l}\text { Load upon completion of the ergometer test, Wt and second coordinimeter } \\
\text { test times, sec, time of coordination test }\end{array}$ & -0.637 & 0.05 \\
\hline
\end{tabular}

NB: rS - rate correlations Spearman's

skiers performing physical work at AT the observed increase in oxygen consumption is caused by increased oxygen uptake by muscles, and is not accompanied by excessive increase of lactate levels [16]. In our study in September we observed AT in our participants at higher load and oxygen consumption than in June, with constant lactate level. In our opinion that finding signifies an increase in functional reserves of the oxygen transport system and optimization of physiological processes. It is important to note that maximal oxygen consumption values remained the same, and that the increase of oxygen consumption at anaerobic threshold reflected relative change in the same range (from $77.4 \%(72.6 \% ; 82.9 \%)$ of $\mathrm{VO}_{2 \max }$ in June to $87.6 \%(77.0 \% ; 92.7 \%)$ of $\mathrm{VO}_{2 m}$ in September). Therefore, we concluded that the higher the aerobic performance capacity in athletes, the less is the contribution of anaerobic glycolysis in the maximal ergometer test.

By the end of preparatory period cross country skiers in our study had higher oxygen consumption per $\mathrm{kg}$ of body mass $(53.5 \mathrm{ml} / \mathrm{min} / \mathrm{kg})$ than ski runners $(37.6 \mathrm{ml} /$ $\min / \mathrm{kg}$ ) similar by anthropometric characteristics to our group did [18]. Increased minute respiratory volume at anaerobic threshold in ski runners, probably, was a consequence of increased physical load and power that increased oxygen consumption and respiratory volume. The so called "sport type of breathing", characterized by increased respiratory volume and decreased rate, is considered more economical [17]; we observed exactly such changes in September ( $p>0.05)$.

In maximal physical exercise the main performance criteria are considered to be parameters of effectiveness and economy: watt-pulse, oxygen pulse, oxygen utilization quotient [19]. In our study we observed an improvement in those parameters, both on AT and at the time of voluntary termination of the test.

Recovery is characterized by different involvement of various parameters of functional economy and effectiveness [19]. Higher oxygen utilization quotient reflects more effective oxygen utilization when accompanied with trends towards decrease in minute respiration volume and oxygen consumption. We believe 
that it is caused by changes in the gas exchange in lungs, decreased speed of blood flow through lung vessels that gives erythrocytes more time to expel $\mathrm{CO}_{2}$ and absorb $\mathrm{O}_{2}$ [20].

Physical exercises aimed at development of aerobic capacity and performance [21] supposedly caused the significant decrease of heart rate $(p<0.05)$ in September in comparison with June, that, in our opinion, reflected more economical work of circulation in athletes.

Skeletal muscles are not the key producers of lactate in physical exercise, they are also tissues that utilize lactate [22]. Our opinion is that the observed decrease of plasma lactate at the $5^{\text {th }}$ minute of recovery (in September in comparison with June) was a marker of adaptation to TE [23].

In June we observed no significant correlations between parameters that we monitored. In September, however, at AT we observed strong and significant negative correlations between oxygen consumption per $\mathrm{kg}$ of body mass and power, between time of roller ski test completion and competition rating in RUS points. It is known from previous studies of that subject that in athletes competing in cyclic sports that rely on endurance the parameters of performance at AT correlate significantly with competitions results [24].

Oxygen consumption at AT seem to correlate positively with speeds achieved when running ski [15]. It is known $[12,25]$, that the effectiveness of motional activity is a very specific feature characterizing coordination abilities and depends on the physiological indicators of the athlete, which is reflected in the ratio of the indicator of the effectiveness of physical work fulfillment wattpulse -and time of fulfillment second coordination test. The correlation between exercise power, oxygen pulse, and the time of the coordination test after the test "to failure" may probably reflect the ability to maintain high coordination abilities under conditions of greater fatigue as a result of performing a higher load after PP. The statistically significant correlations that emerged after PP may indicate the formation of closer priority relationships between the indicators of cardio respiratory system, physical performance, and coordination of movements, which indicates an increase in the functional capabilities of the body, contributing to the growth of sports results.

\section{Conclusions}

The results of the study showed that the proposed program for the summer-autumn training period contributes to the improvement of the functional status of the cross-country skiers and to the development of physical power, endurance, increased strength of the upper limbs, increased speed of movement on roller skis, faster and more complete recovery of physiological and biochemical parameters. The proposed program for the summer-autumn training period helped in improving the athletes' functional status, and can be recommended for the development of physical qualities in highly qualified cross-country skiers and for improvement of physical performance.

\section{Funding}

This study was carried out as part of the study of metabolic support of physical performance in humans in the North and the development of performance increase methods within the framework of the basic budget financing (No. GRAAAA-A17-117012310157-7).

\section{Conflict of interests}

The authors declare no conflict of interest.

\section{References}

1. Losnegard T, Mikkelsen K, Rønnestad BR, Hallern J, Rud B, Raastad T. The effect of heavy strength training on muscle mass and physical performance in elite cross country skiers. Scand J Med Sci Sports. 2011; 21: 389-401. https://doi.org/10.1111/j.1600-0838.2009.01074.x

2. Losnegard $T$, Myklebust $H$, Spencer M, Hallén J. Seasonal Variations in $\mathrm{VO}_{2} \max , \mathrm{O}_{2}$-Cost, $\mathrm{O}_{2}$-Deficit, and Performance in Elite Cross-Country Skiers. J. Strength Cond. Res. 2013; 27(7): 1780-1790. https://doi.org/10.1519/JSC.0b013e31827368f6

3. Hedelin R, Wiklund U, Bjerle P, Henriksson-Larse'n K. Preand post-season heart rate variability in adolescent crosscountry skiers. Scand j med \& Sci in Sport. 2000; 6: 98-303. https://doi.org/10.1034/j.1600-838.2000.010005298.x

4. Beattie K, Kenny IC, Lyons M, Carson BP. The Effect of Strength Training on Performance in Endurance Athletes. Sports Med. 2014; 44:845-865. https://doi.org/10.1007/s40279-014-0157-y

5. Rønnestad BR, Mujika I. Optimizing strength training for running and cycling endurance performance: A review. Scand J Med Sci Sports. 2014; 24: 603-612. https://doi.org/10.1111/sms.12104

6. Choi Chul Y. The effect of 3 weeks high altitude skiing training on isokinetic muscle function of cross- country skiers. J Korea Conv Soc. 2018;9:465-77. https://doi.org/10.15207/JKCS.2018.9.11.465

7. Paavolainen L, Häkkinen K, Rusko H. Effects of explosive type strength training on physical performance characteristics in cross-country skiers. Eur J Appl Physiol Occup Physiol. 1991; 62: 251-255. https://doi.org/10.1007/BF00571548

8. Skattebo Ø, Hallén J, Rønnestad B R, Losnegard T. Upper body heavy strength training does not affect performance in junior female cross-country skiers. Scand J Med Sci Sports. 2016; 26(9):1007-16. https://doi.org/10.1111/sms.12517

9. Øfsteng S, Sandbakk Ø, van Beekvelt M, Hammarström D, Kristoffersen R, Hansen J, et al. Strength training improves double-poling performance after prolonged submaximal exercise in cross-country skiers. Scand J Med Sci Sports, 2018;28:893-904. https://doi.org/10.1111/sms.12990

10.Bojko ER. Physiological and biochemical mechanisms to ensure the sports activities of winter cyclic sports. Syktyvkar: LLC Komi republic printing office; 2019. (in Russian).

11.Lyudinina AYu, Ivankova GE, Bojko ER. Priority use of medium-chain fatty acids during high-intensity exercise in cross-country skiers. J Int Soc Sports Nutr, 2018;15:57. https://doi.org/10.1186/s12970-018-0265-4 
12.Garnov IO, Varlamova NG, Loginova TP, Potolitsyna NN, Chernykh AA, Bojko ER. Effects of the maximal bicycle ergometric load test on coordination abilities and functional state of cross-country skiers and biathletes. Russian Journal of Biomechanics. 2019;2:143 - 150. https://doi.org/10.15593/RZh Biomeh/2019.2.01

13.Cross country skiing Federation of Russia. RUS points. [Internet]. 2020 [updated 2018 Jun 15; cited 2020 Nov 5]. (in Russian). Available from: http://www.flgr.ru/Results

14. Youdas JW, Amundson CL, Cicero KS, Hahn JJ, Harezlak DT, Hollman JH. Surface electromyographic activation patterns and elbow joint motion during a pullup, chin-up, or perfect-pullup TM rotational exercise. $J$ Strength and Cond Res. 2010; 24(12): 3404-3414. https://doi.org/10.1519/JSC.0b013e3181f1598c

15.Popov DV, Vinogradova OL. Comparison of the aerobic performance of leg and arm muscles in cross-country skiers. Human Physiology. 2012;38 (5): 508-513. https://doi.org/10.1134/S0362119712050106

16.Gilbert C. Optimal physical performance in athletes: key roles of dopamine in a specific neurotransmitter/ hormonal mechanism. Mech Ageing Dev. 1995; 84: 83-102. https://doi.org/10.1016/0047-6374(95)01635-X

17.Bojko ER. Metabolic providing an annual cycle of adaptive reactions of cardiovascular and respiratory systems at the military personnel on north conditions. Federal Research Centre Komi Science Centre of the Ural Branch of the Russian Academy of Sciences. Syktyvkar; 2007. (in Russian). 18.Krivoschekov SG, Divert VE, Melnikov VN, Vodjanitskij
SN, Girenko LA. Comparative analysis of gas exchange and cardiorespiratory system responses of swimmers and skiers to increasing normobaric hypoxia and physical load. Human Physiology. 2013; 39(1): 98-105. (in Russian). https://doi.org/10.1134/S0362119712060072

19.Gorbaneva EP. Qualitative characteristics of functional preparedness of athletes. Saratov: Sciencebook; 2008. (in Russian).

20.Popov DV, Vinogradova OL. Aerobic performance: role of oxygen delivery and utilization, glycolytic flux. Progress in Physiological Science. 2012; 43(1): 30-47. (in Russian).

21.Blomqvist CG, Saltin B. Cardio vascular adaptation to physical training. Ann Rev Physiol. 1983; 45:169-189. https://doi.org/10.1146/annurev.ph.45.030183.001125

22.Hashimoto T, Brooks GA. Mitochondrial Lactate Oxidation Complex and an Adaptive Role for Lactate Production. Med Sci Sports Exerc. 2008; 40(3): 486 - 494. https://doi.org/10.1249/MSS.0b013e31815fcb04

23.Jacobs I. Blood Lactate: Implications for Training and Sports Performance. Sports Med. 1986; 3(1):10-25. https://doi.org/10.2165/00007256-198603010-00003

24.Komi P, Ito A, Sjödin B, Wallenstein R, Karlsson J. Muscle Metabolism, Lactate Breaking Point, and Biomechanical Features of Endurance Running. Int $J$ Sports Med, 1981; 2:148-53. https://doi.org/10.1055/s-2008-1034602

25.Lyakh VI. Coordination skills: Diagnosis and development. Moscow: TVT Divizion; 2006. (in Russian).

\section{Information about the authors:}

Igor O. Garnov; (Corresponding author); https://orcid.org/0000-0002-2604-2773; 566552@inbox.ru; M.D., Ph. D. (Biology), Scientist of the Department of Ecological and Medical Physiology of the Institute of Physiology of the Komi Science Center of the Ural Branch of the Russian Academy of Sciences; Pervomayskaya st. 50, Syktyvkar, GSP - 2, 167982, Russian Federation.

Tatyana P. Loginova; https://orcid.org/0000-0001-7003-6664; log73tag@yandex.ru; M.D., Ph.D. (Biology), Scientist of the Department of Ecological and Medical Physiology of the Institute of Physiology of the Komi Science Center of the Ural Branch of the Russian Academy of Sciences; Pervomayskaya st. 50, Syktyvkar, GSP - 2, 167982, Russian Federation.

Nina G. Varlamova; https://orcid.org/0000-0003-1444-4684; nivarlam@physiol.komisc.ru; M.D., Ph.D. (Biology), Senior Researcher of the Department of Ecological and Medical Physiology of the Institute of Physiology of the Komi Science Center of the Ural Branch of the Russian Academy of Sciences; Pervomayskaya st. 50, Syktyvkar, GSP - 2, 167982, Russian Federation.

Natalya N. Potolitsyna; https://orcid.org/0000-0003-4804-6908; potol_nata@list.ru; M.D., Ph.D. (Biology), Scientist of the Department of Ecological and Medical Physiology of the Institute of Physiology of the Komi Science Center of the Ural Branch of the Russian Academy of Sciences. Pervomayskaya st. 50, Syktyvkar, GSP - 2, 167982, Russian Federation.

Alexey A. Chernykh; https://orcid.org/0000-0002-1574-5588; death.elephant@gmail.com; Junior Researcher of the Institute of Physiology of the Komi Science Centre of the Ural Branch of the Russian Academy of Sciences. Pervomayskaya st. 50, Syktyvkar, GSP - 2, 167982, Russian Federation.

Evgeniy R. Bojko; https://orcid.org/0000-0002-8027-898X; boiko@inbox.ru; M.D., D.Sc. (Medicine), Prof., Director of the Institute of Physiology of the Komi Science Center of the Ural Branch of Russian Academy of Science; Pervomayskaya st. 50, Syktyvkar, GSP - 2, 167982, Russian Federation.

Cite this article as:

Garnov IO, Loginova TP, Varlamova NG, Potolitsyna NN, Chernykh AA, Bojko ER. Functional state dynamics in cross-country skiers in the summer and autumn preparatory phase. Pedagogy of Physical Culture and Sports, 2021;25(3):152-159. https://doi.org/10.15561/26649837.2021.0302

This is an Open Access article distributed under the terms of the Creative Commons Attribution License, which permits unrestricted use, distribution, and reproduction in any medium, provided the original work is properly cited (http://creativecommons.org/licenses/by/4.0/deed.en). 